\title{
Survival as power
}

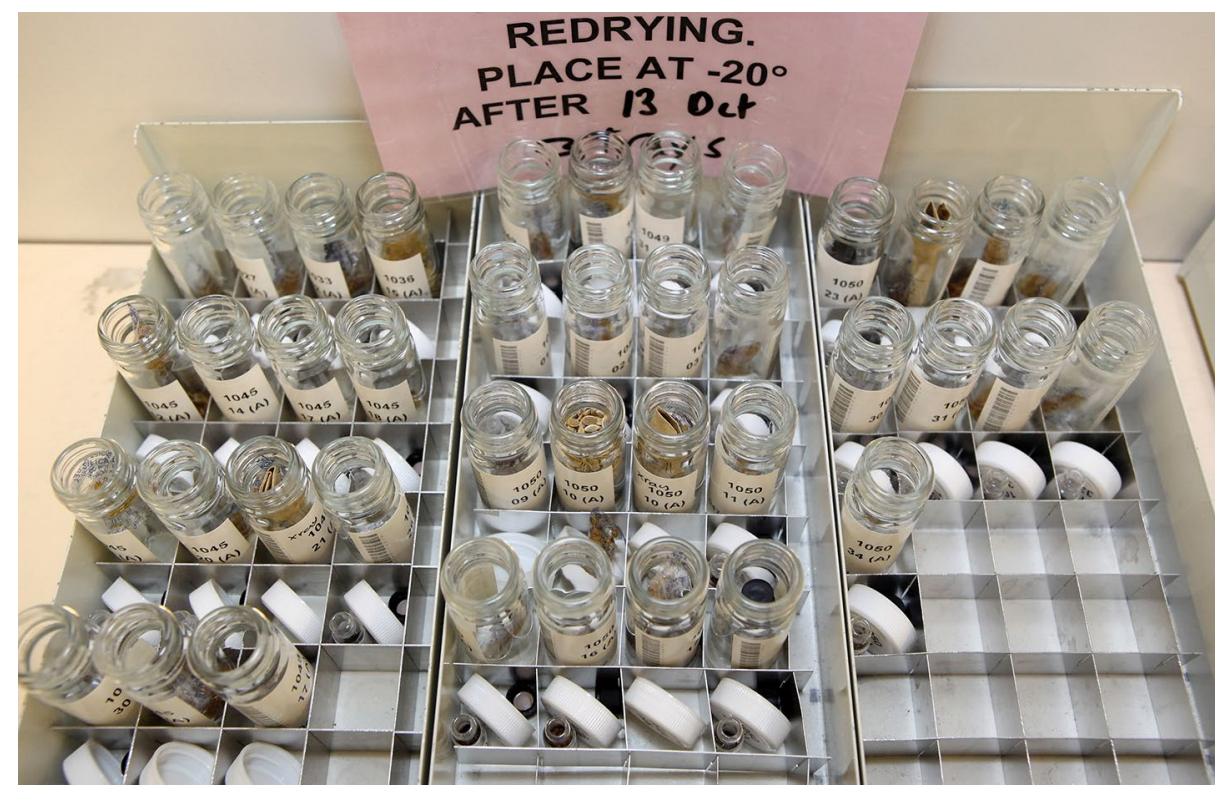

Credit: Oli Scarff/Staff/Getty Images News

The creation of seed banks is undoubtedly a major advance for conservationists around the world in the face of biodiversity loss and ecological degradation, but there are legitimate questions to be raised about the type of power seed banks enjoy over what kinds of species get to live and why.

Sara Peres at the University of Southampton researched not only the role that the Food and Agriculture Organization and the Consultative Group on International Agricultural Research (CGIAR) played in establishing the International Board on Plant Genetic Resources (IBPGR), but also the philosophies that drove the scientific development of cryogenic technology for seed storage. Peres notes that while researchers debated the viability of seeds for freezing, which itself could limit which species could be saved, there were also pressures on and from agribusiness to focus efforts on 'useful' species. For example, CGIAR's focus on the Green Revolution limited and guided resources for many collections and banks. This history is viewed through the framework of 'cryopower', in which the institutions guided by the IPBGR's view of seeds as a 'resource' to be maintained as a time-stable and globally provided good shaped the development of the seed banks and created a social, political and technological 'coldscape' for the future of plants and humanity.

\section{Ryan Scarrow}

Published online: 13 February 2020 https://doi.org/10.1038/s41477-020-0608-4 